\title{
Cluster of differentiation 45 activation is crucial in interleukin-10-dependent tumor-associated dendritic cell differentiation
}

\author{
DA-EN CHENG ${ }^{1 *}$, YING-MING TSAI ${ }^{2 *}$, YA-LING HSU $^{1}$, MING-FENG HOU $^{3}$, EING-MEI TSAI $^{1}$, \\ JAW-YUAN WANG ${ }^{3}$, JUNG-YU KAN ${ }^{3}$ and PO-LIN KUO ${ }^{3,4}$ \\ ${ }^{1}$ Graduate Institute of Medicine, College of Medicine, Kaohsiung Medical University; ${ }^{2}$ Division of Pulmonary \\ and Critical Care Medicine, Kaohsiung Medical University Hospital; ${ }^{3}$ Institute of Clinical Medicine, \\ College of Medicine, Kaohsiung Medical University; ${ }^{4}$ Department of Medical Research, \\ Kaohsiung Medical University Hospital, Kaohsiung 807, Taiwan, R.O.C.
}

Received November 25, 2013; Accepted May 6, 2014

DOI: $10.3892 / \mathrm{ol} .2014 .2161$

\begin{abstract}
Tumor-associated dendritic cells (TADCs) are important in tumor immune surveillance, and it has been reported that the secretion of interleukin (IL)-10 by cancer cells is a major factor involved in the induction of TADCs in the tumor microenvironment. In the present study, IL-10 was found to activate cluster of differentiation (CD) 45 protein tyrosine phosphatase (PTPase), inducing a TADC-like phenomenon. The PTPase inhibitor, phenylarsine oxide, and a CD45 inhibitor reversed the IL-10-induced impaired differentiation of the DCs, and also reversed the induction of the TADCs by A549, MDA-MB-231 and SW480 conditioned media, which thus represents a novel therapy to reduce immune surveillance in the tumor microenvironment. The present study is the first to identify that CD45 is involved in IL-10-activated signaling in myeloid lineage cells.
\end{abstract}

\section{Introduction}

Dendritic cells (DCs) are antigen-presenting cells with the unique ability to take up and process antigens in the peripheral blood and tissues (1). Subsequent migration to the draining lymph nodes then occurs, where the antigens are presented to resting lymphocytes. Antigen ingestion and processing is particularly efficient within immature DCs, however, for an

Correspondence to: Professor Po-Lin Kuo, Institute of Clinical Medicine, College of Medicine, Kaohsiung Medical University, 100 Shih-Chuan First Road, Kaohsiung 807, Taiwan, R.O.C.

E-mail: kuopolin@seed.net.tw

${ }^{*}$ Contributed equally

Key words: cluster of differentiation 45, interleukin-10, monocytes, tumor-associated dendritic cells efficacious T-cell response, maturation to fully activated DCs must occur; these cells express high levels of cell-surface major histocompatibility complex (MHC)-antigen complexes and costimulatory molecules. Tumor-associated dendritic cells (TADCs) are DCs that present in the tumor microenvironment with tolerogenic or suppressive functions, which exhibit lower expression levels of costimulatory and MHC molecules (2). TADCs have also been associated with a higher expression level of tolerogenic mediators, including indoleamine-2,3-dioxygenase, arginase and transforming growth factor (TGF)- $\beta$ (3). In addition to inducing immune surveillance, TADCs have been reported to secrete factors that increase cancer progression (4-6).

Previous studies have shown that tolerogenic DCs (tDCs) may be induced by the presence of interleukin (IL)-10 in culture medium or in the tumor microenvironment (7-9). The binding of IL-10 and the IL-10 receptor has been reported to trigger several downstream pathways in mononuclear cells, including the Janus kinase (JAK)-1/signal transducer and activator of transcription-3 (STAT-3) $(10,12)$, p38 mitogen-activated protein kinase, extracellular signal-regulated kinase and c-Jun N-terminal kinase signaling pathways (12). Among the signaling induced by IL-10, the JAK/STAT3 signaling pathway has been reported to be regulated by a group of protein tyrosine phosphatases (PTPases), termed suppressors of cytokine signaling $(13,14)$.

Cluster of differentiation (CD) 45 is a member of the PTPase family that is distributed in the plasma membrane of hematopoietic cells, with the exception of erythrocytes and platelets, and exhibits a crucial function in T-cell receptor-mediated signaling. Previous studies have shown that CD45 also regulates JAK (15-17) and Src $(18,19)$ families. In addition, the negative regulation of cytokine receptor signaling by CD45 may explain the loss of CD45 activity observed in several cancer types, including leukemia. CD45 has been found to correlate with the proliferation of myeloma cells, and it may therefore present a potential target for the treatment of multiple myelomas (20). Despite its abundant expression, the function of CD45 in cells of the myeloid lineage is poorly 
understood. Fulcher et al (21) reported that CD45 may be a receptor for galectin-induced cell activation and migration via Syk and protein kinase C signaling in DCs. Previous studies regarding the function of CD45 in cancer have focused on myelomas $(22,23)$, however, none of these studies have investigated the function of CD45 in tumor immune surveillance. The present study demonstrated that CD45 activation is important in tumor- and IL-10-induced tDCs.

\section{Materials and methods}

Cell lines, cell cultures and condition medium collection. Human breast adenocarcinoma MDA-MB-231 cells (HTB-26) and human lung adenocarcinoma A549 cancer cells (CCL-185) were obtained from the American Type Culture Collection (Manassas, VA, USA). The human colorectal adenocarcinoma SW620 cells (BCRC 60343) and SW480 (BCRC 60249) cells were purchased from the Bioresource Collection and Research Center (Hsinchu City, Taiwan). The human lung adenocarcinoma A549 cancer cells were cultured in minimum essential medium (Life Technologies, Inc., Grand Island, NY, USA) with 10\% fetal bovine serum (FBS), non-essential amino acids and $0.1 \mathrm{mM}$ sodium pyruvate (all Thermo Fisher Scientific, Waltham, MA, USA). The human breast adenocarcinoma MDA-MB-231 cells were cultured in F12K medium (Life Technologies, Inc.) with 10\% FBS, non-essential amino acids and $0.1 \mathrm{mM}$ sodium pyruvate. The SW620 and SW480 human colorectal adenocarcinoma cells were cultured in Leibovitz's L-15 medium (Life Technologies, Inc.) supplemented with $10 \%$ FBS. The medium was changed once every 2-3 days and the cells were channeled once a distinct cell density had been reached. To obtain the conditioned medium, $2 \times 10^{6}$ cells/well were seeded in a $100 \mathrm{~mm}$ dish and cultured for $24 \mathrm{~h}$. The medium was then replaced and the supernatants were harvested following $48 \mathrm{~h}$ of incubation (Fig. 1).

Reagents and antibodies. Recombinant human granulocyte-macrophage colony-stimulating factor (GM-CSF) and IL-4 were purchased from Millipore (Bedford, MA, USA). Recombinant human IL-10 was purchased from R\&D Systems (Minneapolis, MN, USA). Phenylarsine oxide (PAO), CD45 PTPase inhibitor and PTPase inhibitor XVIII were purchased from Merck Millipore (Bedford, MA, USA). Fluorescein isothiocyanate-conjugated anti-CD16, phycoerythrin-conjugated anti-CD163, anti-CD11c, -CD80,-CD1a and -CD14, and APC-conjugated anti-CD14 monoclonal antibodies (mAbs) were purchased from BD Pharmingen (San Diego, CA, USA).

Monocyte isolation and differentiation. Mononuclear cells were isolated from the blood of healthy donors using the Ficoll-Hypaque gradient (GE Healthcare, Little Chalfont, UK). Approval for this study was obtained from the Institutional Review Board of Kaohsiung Medical University Hospital (Kaohsiung, Taiwan), and informed consent was obtained from all patients in accordance with the Declaration of Helsinki. CD14 ${ }^{+}$monocytes were purified using $\mathrm{CD} 14^{+}$ mAb-conjugated magnetic beads (MACS MicroBeads; Miltenyi Biotec, Bisley, UK) according to the manufacturer's

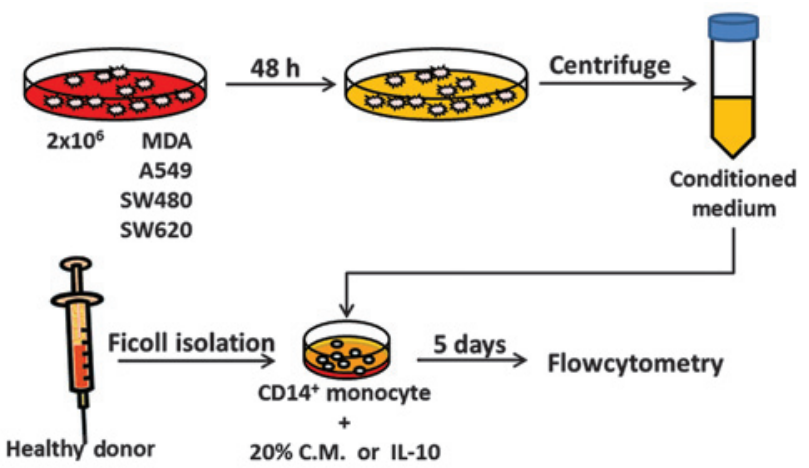

Figure 1. Diagram showing the conditioned medium transfer system. A total of $2 \times 10^{6}$ cancer cells were plated in a $10-\mathrm{cm}$ dish and incubated for $48 \mathrm{~h}$. The supernatant was transferred to a $50-\mathrm{ml}$ centrifuge tube and centrifuged at $1,000 \mathrm{x} \mathrm{g}$ for $15 \mathrm{~min}$. CD14 ${ }^{+}$monocytes were isolated from healthy donor peripheral blood mononuclear cells and incubated with $20 \mathrm{ng} / \mathrm{ml}$ granulocyte-macrophage colony-stimulating factor and IL-4 alone or with an additional $20 \%$ cancer cell-conditioned medium or $10 \mathrm{ng} / \mathrm{ml} \mathrm{IL-10} \mathrm{for}$ five days. IL, interleukin; CD14, cluster of differentiation 14.

instructions. A control group of monocyte-derived dendritic cells was generated by culturing $\mathrm{CD} 14^{+}$monocytes in RPMI 1640 medium containing 10\% FBS (Invitrogen Life Technologies, Carlsbad, CA, USA), 20 ng/ml GM-CSF and $20 \mathrm{ng} / \mathrm{ml} \mathrm{IL-4} \mathrm{(Millipore)} \mathrm{for} \mathrm{five} \mathrm{days.} \mathrm{In} \mathrm{the} \mathrm{IL-10,} \mathrm{A549,}$ SW480, SW620 and MDA groups, an additional $10 \mathrm{ng} / \mathrm{ml}$ IL-10 (R\&D Systems) or $20 \%$ cancer cell-conditioned medium was added. The medium was replaced with fresh medium containing GM-CSF and IL-4 on day three. Following five days of incubation, the presence of CD14 and other surface markers was determined by fluorescence-activated cell sorting array flow cytometry using fluorochrome-conjugated mAbs (BD Pharmingen) (Fig. 1).

Assessment of CD45 PTPase activity. CD14+ monocytes were incubated in RPMI containing GM-CSF and IL-4 with or without IL-10 for $30 \mathrm{~min}$. The activity of CD45 PTPase was determined by a Human Active CD45 activity assay (R\&D Systems) according to the manufacturer's instructions. Briefly, 5x10 ${ }^{6} \mathrm{CD}^{+} 4^{+}$monocytes in $200 \mu \mathrm{l}$ lysis buffer and $100 \mu \mathrm{l}$ lysate were applied to the assay plate. Absorbance at $620 \mathrm{~nm}$ was measured using the Biotek Powerwave 340 ELISA reader (BioTek Instruments, Inc., Winooski, VT, USA).

Statistical analysis. Data are presented as the mean \pm standard deviation. Statistical analyses were performed by analysis of variance and two-sided t-tests using Excel 2010 (Microsoft, Tulsa, OK, USA). P<0.05 was considered to indicate a statistically significant difference between the means of the two test groups.

\section{Results}

IL-10 may induce TADC-like DCs. The monocytes isolated from the healthy donors were treated with $20 \mathrm{ng} / \mathrm{ml}$ GM-CSF and IL-4 and incubated for five days for differentiation into resting DCs. In the MDA-MB-231 and IL-10 

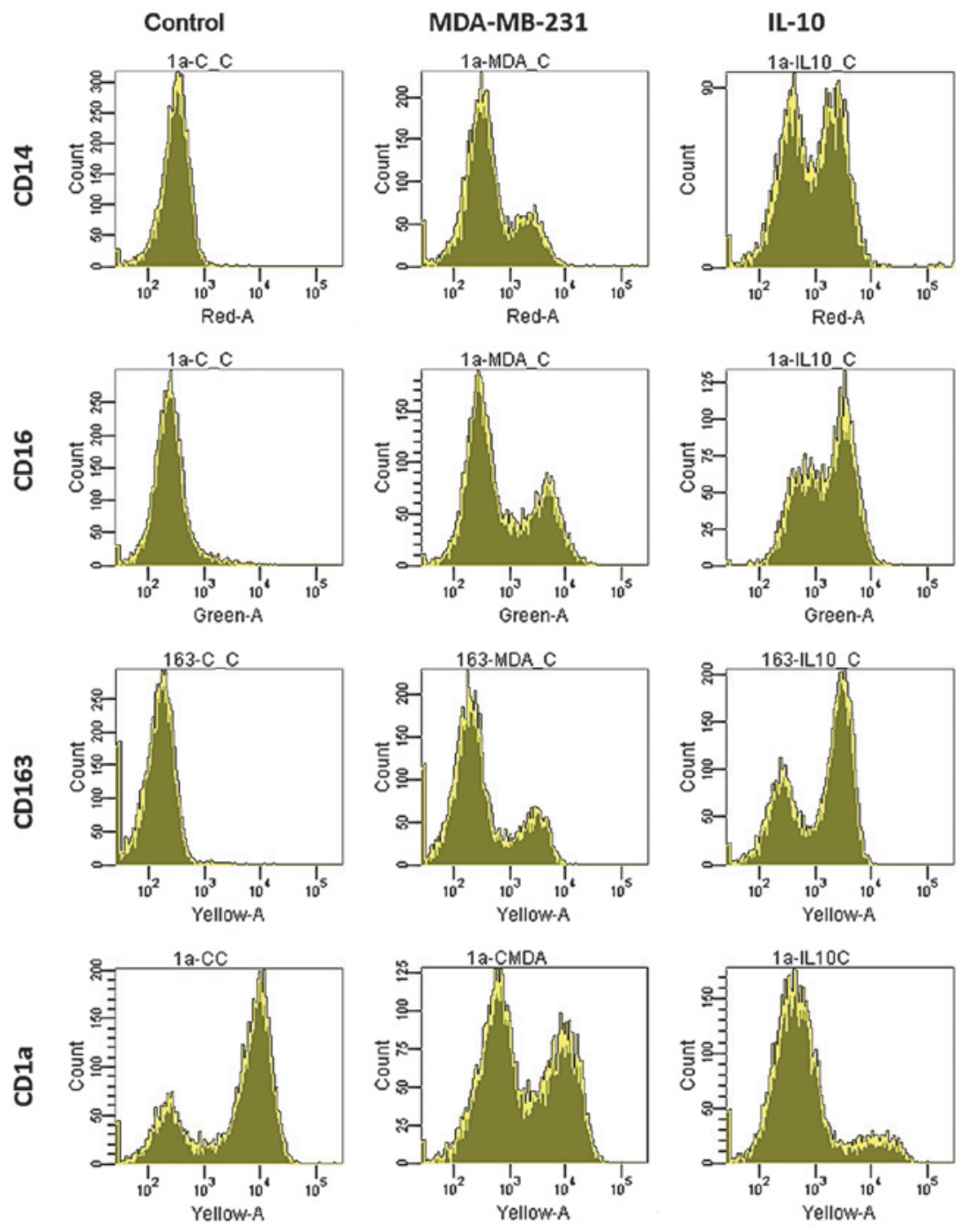

Figure 2. IL-10 induces tumor-associated dendritic cell-like surface marker expression. CD14+ monocytes were incubated with $20 \mathrm{ng} / \mathrm{ml}$ granulocyte-macrophage colony-stimulating factor and IL-4 alone or with an additional $20 \%$ MDA-MB-231-conditioned medium or $10 \mathrm{ng} / \mathrm{ml} \mathrm{IL-10} \mathrm{for} \mathrm{five} \mathrm{days.} \mathrm{The} \mathrm{cells} \mathrm{were}$ stained with antigen-presenting cell conjugated anti-CD14 mAb, fluorescein isothiocyanate-conjugated anti-CD16 mAb, PE-conjugated anti-CD11c mAb and PE-conjugated anti-CDla mAb. The fluorescence intensity was determined by a fluorescence-activated cell sorting array flow cytometry system. All results are representative of at least three independent experiments. IL, interleukin; $\mathrm{CD}$, cluster of differentiation; mAb, monoclonal antibody; PE, phycoerythrin.

groups, an additional $20 \%$ of MDA-MB-231 breast cancer cell-conditioned medium and $10 \mathrm{ng} / \mathrm{ml} \mathrm{IL}-10$ was added. Following five days of incubation, the MCF and IL-10 groups exhibited a different expression pattern of surface markers when compared with the control group. In the control group, no CD14 expression was detected, however, $25 \%$ of the cells expressed CD14 in the MDA group. In addition, the CD14 expression was higher in the IL-10 group than in the MDA group. CD16 and CD163 expression showed the same pattern as CD14 in the three groups, in contrast to the expression of CD1a (Fig. 2). However, no significant differences were identified in the expression of CD80 and CD11c in the three groups (data not shown).

CD45 PTPase is involved in IL-10-induced impaired $D C$ differentiation. To investigate whether the PTPases are involved in IL-10 signaling, three types of PTPase inhibitors were used in the present study. PAO is a general A membrane-permeable protein tyrosine phosphatase inhibitor, and PTP inhibitor XVIII inhibits the enzymatic activity of PTP1B, tyrosine-protein phosphatase non-receptor type 6, pathogenic Yersinia PTPase (YOP), T-cell protein tyrosine phosphatase, and yeast PTP1. PTP CD45 inhibitor (CD45i) is a selective and reversible inhibitor of CD45. Prior to the addition of IL-10 and GM-CSF/IL-4 to the culture medium, the $\mathrm{CD} 14^{+}$monocytes isolated from the healthy donors were incubated with the different inhibitors for $1 \mathrm{~h}$. Following five days of incubation, the higher CD14 expression level mediated by IL-10 was reversed by the PAO and CD45 inhibitors, however, the CD14 expression of the DCs was not found to be downregulated by PTP inhibitor XVIII (Fig. 3A and B). The activation of CD45 was also confirmed by a CD45 tyrosine phosphatase assay kit (Enzo Life Sciences, Inc., Farmingdale, NY, USA), which showed that IL-10 activated CD45 phosphatase activity (Fig. 3C).

$P A O$ and $C D 45 i$ reduces the number of tumor-mediated TADCs. To investigate whether PAO and CD45i were able 
A

Control

IL-10
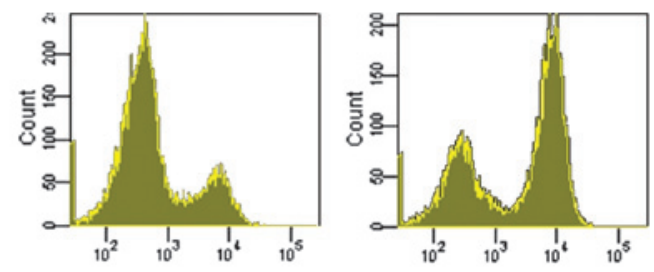

IL-10 + PAO

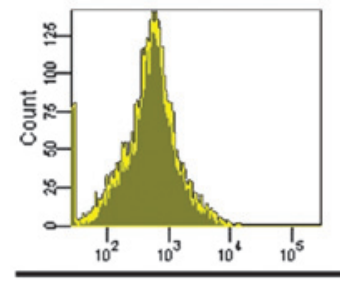

IL-10+ CD45 i.

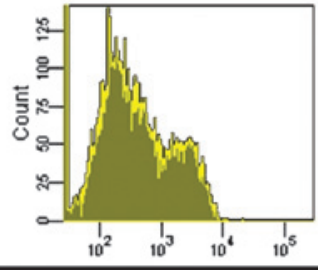

IL-10 + PTPi. 18

B

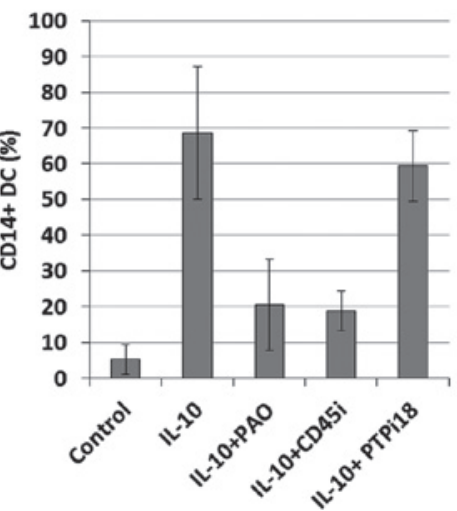

C
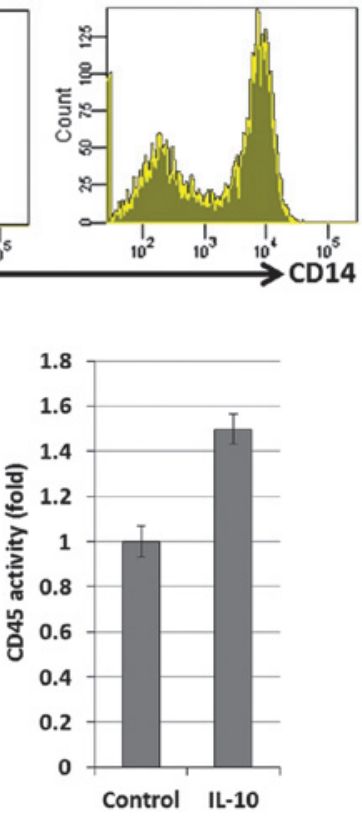

Figure 3. CD45 is involved in the IL-10 induction of tumor-associated dendritic cell-like DCs. (A and B) CD14 monocytes were treated with $10 \mu \mathrm{M}$ PAO, $100 \mathrm{nM}$ CD45 PTPase inhibitor (CD45 i.) or $50 \mathrm{nM}$ PTP inhibitor XVIII (PTPi. 18) for $1 \mathrm{~h}$. The cells were later incubated with IL-10 (10 ng/ml) containing medium without or with $(20 \mathrm{ng} / \mathrm{ml})$ GM-CSF and IL-4 for five days. The surface expression of CD14 was assessed by phycoerythrin-conjugated anti-CD14 monoclonal antibody and a fluorescence-activated cell sorting array flow cytometry system. (C) CD14 $4^{+}$monocytes were incubated in RPMI containing GM-CSF and IL-4 with or without IL-10 for 30 min, and the activity of CD45 PTPase was determined using a CD45 Tyrosine Phosphatase assay kit. All results are representative of at least three independent experiments. Each value is presented as the mean \pm standard deviation of three experiments. $\mathrm{CD}$, cluster of differentiation; IL, interleukin; DC, dendritic cell; PTP, protein tyrosine phosphatase; GM-CSF, granulocyte-macrophage colony-stimulating factor; PAO, phenylarsine oxide.

to block the differentiation of the TADCs, the conditioned medium of the varying cancer types, including that of the lung (A549), breast (MDA-MB-231) and colorectal cancer (SW480 and SW620) cells, was collected. The CD14+ monocytes isolated from the healthy donors were treated with PAO or CD45i prior to the addition of $20 \%$ cancer cell-conditioned medium. Following five days of incubation, the surface CD14 expression was determined, and it was found that PAO and CD45i reversed cancer cell-mediated TADC differentiation in the IL-10, A549, MDA and SW480 groups (Fig. 4A). However, only PAO, but not CD45i, reversed the induction of TADCs by SW620 (Fig. 4B).

\section{Discussion}

DCs are antigen-presenting cells of hemopoietic origin with potent effects on primary T-cell differentiation and activation, and are thus of central relevance to antitumor immune responses and vaccine development $(24,25)$. However, normal DC function is usually impaired in cancer patients $(26,27)$. Previous studies have shown that immature or tDCs are induced by vascular endothelial growth factor and IL-10 (28-30), which is consistent with the results of the present study (Fig. 2). In the current study, cancer cell-conditioned medium and IL-10 induced higher expression levels of CD14, CD16 and CD163 with normal DC markers, including CD11c and CD209. This indicates that the TADCs or IL-10-induced DCs were similar to the circulating tDC-10 (31).

The IL-10 receptor (IL-10R) is a receptor tyrosine kinase, and the binding of IL-10 and IL-10R activates the JAK1 signaling pathway and its downstream factors, including STAT3, phosphoinositide 3-kinase (PI3K) and p38 $(13,32,33)$. Notably, CD45 has been reported to not only regulate the JAK/STAT3 pathway (17), but also to activate p38 in $\mathrm{B}$ cells (34) and PI3K in monocytes (35). This indicates that CD45 may regulate the IL-10-mediated signaling pathway. The results of the present study also support the hypothesis that CD45 is crucial in the IL-10 signaling pathway. The general PTPase inhibitor, PAO, and CD45i reversed the IL-10-induced TADCs, however, PTP inhibitor XVIII was not found to block CD45 activity or the IL-10-mediated differentiation of the TADCs. These results also indicate that additional PTPases 
A
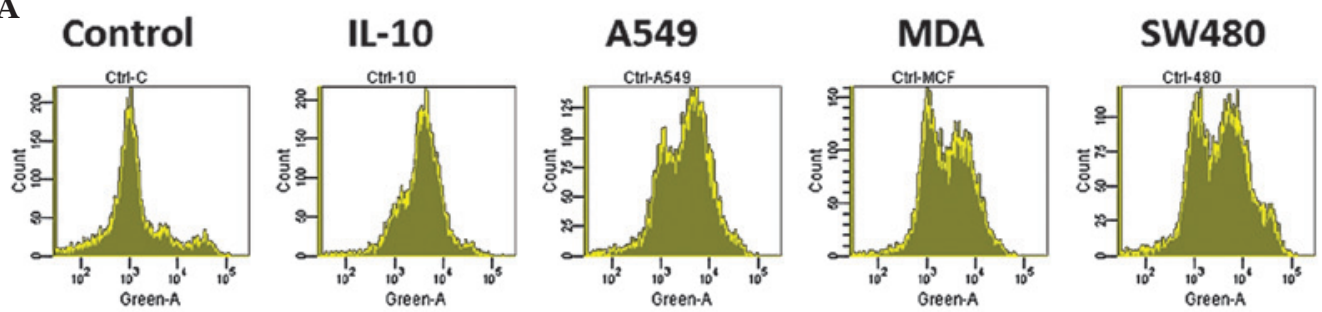

SW620
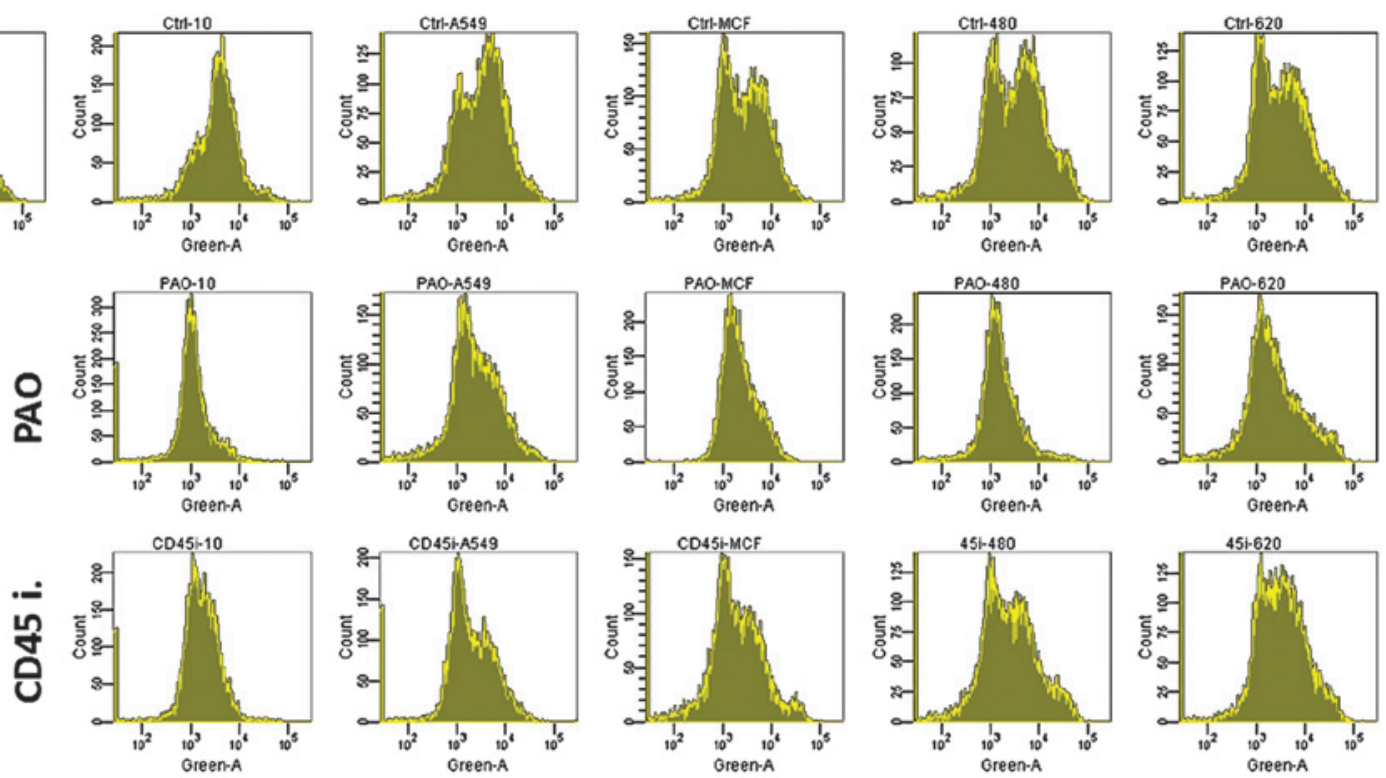

B

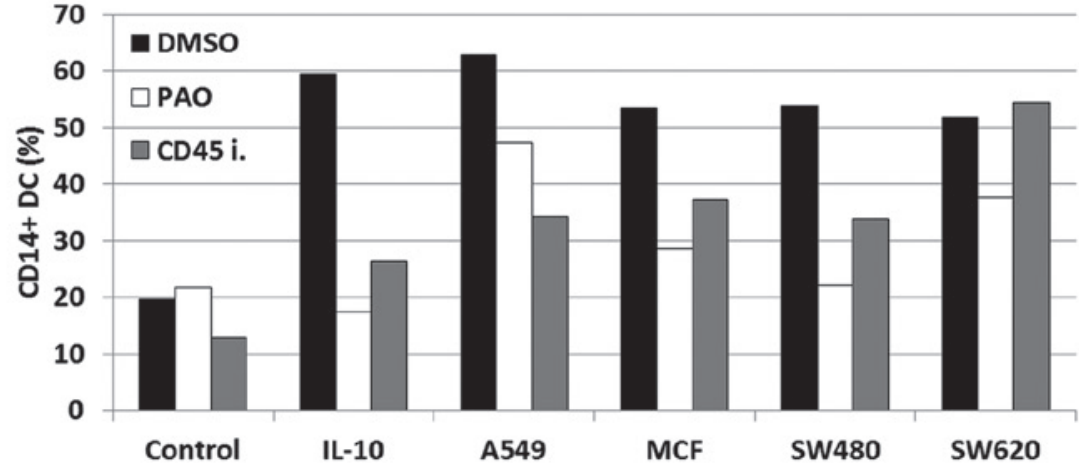

Figure 4. PAO and CD45 inhibitor reverse cancer cell-induced tumor-associated dendritic cells. (A and B) CD14 ${ }^{+}$monocytes were incubated in culture medium containing $20 \mathrm{ng} / \mathrm{ml}$ granulocyte-macrophage colony stimulating factor and IL-4 with or without different $20 \%$ cancer cell-conditioned media for 5 days. The surface expression of CD14 was assessed by phycoerythrin-conjugated anti-CD14 monoclonal antibody and a fluorescence-activated cell sorting array flow cytometry system. All results are representative of at least three independent experiments, one of which is shown. PAO, phenylarsine oxide; IL, interleukin; $\mathrm{CD}$, cluster of differentiation; DMSO, dimethyl sulfoxide.

may not be involved in the IL-10 induction of TADCs. In addition, PAO and the CD45i were not found to impair normal DC differentiation (data not shown). PAO appeared to exhibit an increased efficacy in blocking the differentiation of TADCs, which may be due to the multiple targets of PAO, including internalization of ligand-receptor complexes (36), protein kinase C activity, phosphotyrosine phosphatase (37) and formyl peptide-stimulated and phorbol ester-stimulated phospholipase D (38). Therefore the present study indicates that PAO or a novel signaling pathway of IL-10 may represent a novel target.

Notably, PAO was found to completely block the differentiation of the TADCs induced by cancer cell-conditioned medium, however, CD45i was not found to block the induction of TADCs in SW620-conditioned medium. This suggests that SW620 may secrete factors other than IL-10 to induce TADCs. The comparison between SW620 and SW480 is a well-established model used to study the metastasis of colorectal cancer, whereby SW620 cells are isolated from the metastatic lymph nodes of the patients from whom SW480 cells are isolated. Furthermore, secretome studies have revealed that SW620 cells may secrete trefoil factor 3, growth/differentiation factor 15 (39), chemokine (C-X-C motif) ligand 8 (40), galectin-1 (41), TGFs and platelet-derived growth factor (42-44). Further studies to investigate the abilities of these factors in TADC induction are required, and the pathways also require clarification to prevent immune surveillance in distal metastatic organs. In conclusion, the present study is the first to demonstrate that CD45 PTPase activity is required for IL-10-mediated TADC differentiation, and that PAO and CD45 inhibitors block this process, which indicates that there is potential for the use of small molecules to modulate the immune system in the tumor microenvironment.

\section{Acknowledgements}

This study was supported by Biosignature in Colorectal Cancers, Academia Sinica, Taiwan, the National Science 
Council of Taiwan (grant nos. NSC99-2320-B-037-014-MY3, 101-2628-B-037-001-MY3, 102-2628-B-037-002-MY3, 101-2320-B-037-043-MY3, 102-2632-B-037-001-MY3 and 102-2314-B-037-035-MY3), theExcellenceforCancerResearch Center Grant, the Ministry of Health and Welfare, Executive Yuan, Taipei, Taiwan (grant no. MOHW103-TD-B-111-05) and the Kaohsiung Medical University Hospital (grant nos. KMUH101-1M09 and KMUH101-1M24). The authors would like to thank the Center for Resources, Research and Development of Kaohsiung Medical University for their support with instrumentation.

\section{References}

1. Steinman RM: The dendritic cell system and its role in immunogenicity. Annu Rev Immunol 9: 271-296, 1991.

2. Nestle FO, Burg G, Fäh J, Wrone-Smith T and Nickoloff BJ: Human sunlight-induced basal-cell-carcinoma-associated dendritic cells are deficient in $\mathrm{T}$ cell co-stimulatory molecules and are impaired as antigen-presenting cells. Am J Pathol 150: 641-651, 1997.

3. Watkins SK, Zhu Z, Riboldi E, et al: FOXO3 programs tumor-associated DCs to become tolerogenic in human and murine prostate cancer. J Clin Invest 121: 1361-1372, 2011.

4. Kuo CH, Chen KF, Chou SH, et al: Lung tumor-associated dendritic cell-derived resistin promoted cancer progression by increasing Wolf-Hirschhorn syndrome candidate 1/Twist pathway. Carcinogenesis 34: 2600-2609, 2013.

5. Kuo PL, Huang MS, Cheng DE, Hung JY, Yang CJ and Chou SH: Lung cancer-derived galectin-1 enhances tumorigenic potentiation of tumor-associated dendritic cells by expressing heparin-binding EGF-like growth factor. J Biol Chem 287: 9753-9764, 2012.

6. Hsu YL, Huang MS, Cheng DE, et al: Lung tumor-associated dendritic cell-derived amphiregulin increased cancer progression. J Immunol 187: 1733-1744, 2011.

7. Han Y, Chen Z, Yang Y, et al: Human CD14+ CTLA- $4^{+}$regulatory dendritic cells suppress T cell response via cy totoxic T-lymphocyte antigen-4-dependent IL-10 and indoleamine-2,3-dioxygenase production in hepatocellular carcinoma. Hepatology 59: 567-579, 2013.

8. Lindenberg JJ, Oosterhoff D, Sombroek CC, et al: IL-10 conditioning of human skin affects the distribution of migratory dendritic cell subsets and functional $\mathrm{T}$ cell differentiation. PloS One 8: e70237, 2013.

9. Kuo PL, Hung JY, Huang SK, et al: Lung cancer-derived galectin-1 mediates dendritic cell anergy through inhibitor of DNA binding 3/IL-10 signaling pathway. J Immunol 186: $1521-1530,2011$.

10. Lindenberg JJ, van de Ven R, Lougheed SM, et al: Functional characterization of a STAT3-dependent dendritic cell-derived CD14 cell population arising upon IL-10-driven maturation. Oncoimmunology 2: e23837, 2013.

11. Donnelly RP, Dickensheets H and Finbloom DS: The interleukin-10 signal transduction pathway and regulation of gene expression in mononuclear phagocytes. J Interferon Cytokine Res 19: 563-573, 1999.

12. Sato K, Nagayama H, Tadokoro K, Juji T and Takahashi TA: Extracellular signal-regulated kinase, stress-activated protein kinase/c-Jun $\mathrm{N}$-terminal kinase, and p38mapk are involved in IL-10-mediated selective repression of TNF- $\alpha$-induced activation and maturation of human peripheral blood monocyte-derived dendritic cells. J Immunol 162: 3865-3872, 1999.

13. Staples KJ, Smallie T, Williams LM, et al: IL-10 induces IL-10 in primary human monocyte-derived macrophages via the transcription factor Stat3. J Immunol 178: 4779-4785, 2007.

14. Niemand C, Nimmesgern A, Haan S, et al: Activation of STAT3 by IL- 6 and IL-10 in primary human macrophages is differentially modulated by suppressor of cytokine signaling 3 . J Immunol 170: 3263-3272, 2003.

15. Porcu M, Kleppe M, Gianfelici V, et al: Mutation of the receptor tyrosine phosphatase PTPRC (CD45) in T-cell acute lymphoblastic leukemia. Blood 119: 4476-4479, 2012.

16. Xu D and Qu CK: Protein tyrosine phosphatases in the JAK/STAT pathway. Front Biosci 13: 4925-4932, 2008.
17. Irie-Sasaki J, Sasaki T, Matsumoto W, et al: CD45 is a JAK phosphatase and negatively regulates cytokine receptor signalling. Nature 409: 349-354, 2001.

18. McFarland EC, Hurley TR, Pingel JT, Sefton BM, Shaw A and Thomas ML: Correlation between Src family member regulation by the protein-tyrosine-phosphatase CD45 and transmembrane signaling through the T-cell receptor. Proc Natl Acad Sci USA 90: 1402-1406, 1993

19. Hurley TR, Hyman R and Sefton BM: Differential effects of expression of the CD45 tyrosine protein phosphatase on the tyrosine phosphorylation of the lck, fyn, and c-src tyrosine protein kinases. Mol Cell Biol 13: 1651-1656, 1993.

20. Bataille R, Robillard N, Pellat-Deceunynck C and Amiot M: A cellular model for myeloma cell growth and maturation based on an intraclonal CD45 hierarchy. Immunol Rev 194: 105-111, 2003.

21. Fulcher JA, Chang MH, Wang S, et al: Galectin-1 co-clusters CD43/CD45 on dendritic cells and induces cell activation and migration through Syk and protein kinase C signaling. J Biol Chem 284: 26860-26870, 2009.

22. Descamps G, Pellat-Deceunynck C, Szpak Y, Bataille R, Robillard $\mathrm{N}$ and Amiot M: The magnitude of Akt/phosphatidylinositol 3'-kinase proliferating signaling is related to CD45 expression in human myeloma cells. J Immunol 173: 4953-4959, 2004.

23. Ishikawa H, Mahmoud MS, Fujii R, Abroun S and Kawano MM: Proliferation of immature myeloma cells by interleukin- 6 is associated with CD45 expression in human multiple myeloma. Leuk Lymphoma 39: 51-55, 2000.

24. Timmerman JM and Levy R: Dendritic cell vaccines for cancer immunotherapy. Ann Rev Med 50: 507-529, 1999.

25. Théry C and Amigorena S: The cell biology of antigen presentation in dendritic cells. Curr Opin Immunol 13: 45-51, 2001.

26. Dunn GP, Bruce AT, Ikeda H, Old LJ and Schreiber RD: Cancer immunoediting: from immunosurveillance to tumor escape. Nat Immunol 3: 991-998, 2002.

27. Almand B, Resser JR, Lindman B, et al: Clinical significance of defective dendritic cell differentiation in cancer. Clin Cancer Res 6: 1755-1766, 2000.

28. Gabrilovich DI, Chen HL, Girgis KR, et al: Production of vascular endothelial growth factor by human tumors inhibits the functional maturation of dendritic cells. Nat Med 2: 1096-1103, 1996.

29. Steinbrink K, Jonuleit H, Müller G, Schuler G, Knop J and Enk AH: Interleukin-10-treated human dendritic cells induce a melanoma-antigen-specific anergy in CD8(+) T cells resulting in a failure to lyse tumor cells. Blood 93: 1634-1642, 1999.

30. Qin Z, Noffz G, Mohaupt M and Blankenstein T: Interleukin-10 prevents dendritic cell accumulation and vaccination with granulocyte-macrophage colony-stimulating factor gene-modified tumor cells. J Immunol 159: 770-776, 1997.

31. Gregori S, Tomasoni D, Pacciani V, et al: Differentiation of type $1 \mathrm{~T}$ regulatory cells (Tr1) by tolerogenic DC-10 requires the IL-10-dependent ILT4/HLA-G pathway. Blood 116: 935-944, 2010.

32. Bhattacharyya S, Sen P, Wallet M, Long B, Baldwin AS and Tisch R: Immunoregulation of dendritic cells by IL-10 is mediated through suppression of the PI3K/Akt pathway and of IkappaB kinase activity. Blood 104: 1100-1109, 2004.

33. Song GY, Chung CS, Schwacha MG, Jarrar D, Chaudry IH and Ayala A: Splenic immune suppression in sepsis: A role for IL-10-induced changes in P38 MAPK signaling. J Surg Res 83: 36-43, 1999.

34. Arimura Y, Ogimoto M, Mitomo $\mathrm{K}$, et al: CD45 is required for CD40-induced inhibition of DNA synthesis and regulation of c-Jun NH2-terminal kinase and p38 in BAL-17 B cells. J Biol Chem 276: 8550-8556, 2001.

35. Hayes AL, Smith C, Foxwell BM and Brennan FM: CD45-induced tumor necrosis factor alpha production in monocytes is phosphatidylinositol 3-kinase-dependent and nuclear factor-kappaB-independent. J Biol Chem 274: 33455-33461, 1999.

36. Hoffman JF, Linderman JJ and Omann GM: Receptor up-regulation, internalization, and interconverting receptor states Critical components of a quantitative description of $\mathrm{N}$-formyl peptide-receptor dynamics in the neutrophil. J Biol Chem 271: 18394-18404, 1996.

37. Kutsumi H, Kawai K, Johnston RB Jr and Rokutan K: Evidence for participation of vicinal dithiols in the activation sequence of the respiratory burst of human neutrophils. Blood 85: 2559-2569, 1995

38. Planat V, Tronchere H, Record M, Ribbes G and Chap H: Involvement of vicinal dithiols in differential regulation of fMLP and phorbol ester-activated phospholipase D in stimulated human neutrophils. Biochem Biophys Res Commun 218: 847-853, 1996. 
39. Dowling P and Clynes M: Conditioned media from cell lines: a complementary model to clinical specimens for the discovery of disease-specific biomarkers. Proteomics 11: 794-804, 2011.

40. Bailey C, Negus R, Morris A, et al: Chemokine expression is associated with the accumulation of tumour associated macrophages (TAMs) and progression in human colorectal cancer. Clin Exp Metastasis 24: 121-130, 2007.

41. Ghosh D, Yu H, Tan XF, et al: Identification of key players for colorectal cancer metastasis by iTRAQ quantitative proteomics profiling of isogenic SW480 and SW620 cell lines. J Proteome Res 10: 4373-4387, 2011.
42. Ma C, Rong Y, Radiloff DR, et al: Extracellular matrix protein betaig-h3/TGFBI promotes metastasis of colon cancer by enhancing cell extravasation. Genes Dev 22: 308-321, 2008.

43. Coffey RJ Jr, Shipley GD and Moses HL: Production of transforming growth factors by human colon cancer lines. Cancer Res 46: 1164-1169, 1986.

44. Anzano MA, Rieman D, Prichett W, Bowen-Pope DF and Greig R: Growth factor production by human colon carcinoma cell lines. Cancer Res 49: 2898-2904, 1989. 